\title{
Incidences of and genetic parameters for mastitis, claw disorders, and common health traits recorded in dairy cattle contract herds
}

\author{
E. Gernand, ${ }^{\star 1}$ P. Rehbein,$\dagger^{1}$ U. U. von Borstel, $\neq$ and S. König ${ }^{2}$ \\ *Thuringian State Institute of Agriculture, 07743 Jena, Germany \\ †Department of Animal Breeding, University of Kassel, 37213 Witzenhausen, Germany \\ ‡Department of Animal Science, University of Göttingen, 37075 Göttingen, Germany
}

\begin{abstract}
Test-day records for protein yield, protein percent, fat percent and somatic cell score combined with diagnoses for health traits from 19,870 Holstein cows kept in 9 large-scale contract herds in the region of Thuringia, Germany, were used to infer genetic parameters. From an electronic database system for recording diagnoses, 15 health disorders with highest incidences were extracted and grouped into the following 5 disease categories: claw disorders, mastitis, female fertility, metabolism, and ectoparasites. In a Bayesian approach, threshold methodology was applied for binary distributed health disorders and linear models were used for Gaussian test-day observations. Variances and variance ratios for health disorders were from univariate and covariance components among health disorders and between health disorders, and test-day production traits were from bivariate repeatability models. Incidences of health disorders increased with increasing parity and were substantially higher at the beginning of lactation. Only incidences for ectoparasites slightly increased with increasing stage of lactation. Heritabilities ranged from 0.00 for ectoparasites to 0.22 for interdigital hyperplasia. Heritabilities of remaining health disorders were in a narrow range between 0.04 (corpus luteum persistent) and 0.09 (dermatitis digitalis). Clustering diseases into categories did not result in higher heritabilities. The variance ratio of the permanent environmental component was higher than the heritability for the same trait, pointing to the conclusion that non-genetic factors influence repeated occurrence of health problems during lactation. Repeatabilities were relatively high with values up to 0.49 for interdigital hyperplasia. Genetic correlations among selected health disorders were low and close to zero, disproving the assumption that a cow being susceptible for a specific disease is also suscep-
\end{abstract}

Received August 9, 2011.

Accepted November 28, 2011.

${ }^{1}$ Both authors contributed equally to this study.

${ }^{2}$ Corresponding author: sven.koenig@uni-kassel.de tible for other types of health disorders. Antagonistic genetic relationships between test-day protein yield and health disorders were found for ovarian cysts (0.57) and clinical mastitis (0.29). Remaining genetic correlations between diseases and production traits were close to zero. The genetic correlation between clinical mastitis and somatic cell score was 0.69 . This study revealed reliable genetic parameters for health disorders and underlined the possibility of precise health data recording by farmers from contract herds that can be used for genetic evaluation of health traits.

Key words: contract herd, health trait, genetic parameter

\section{INTRODUCTION}

A system of contract or cooperator herds for improving dairy cattle breeding programs in Germany has been suggested by Schierenbeck et al. (2011). The advantages of selecting specific herds for a close collaboration with the local breeding organization are based on the aspects of an accurate genetic differentiation in superior environments, on improved logistics in the era of genomic selection, and on the possibility of recording additional functional health traits. For the region of Thuringia, characterized by large-scale dairy farms, Gernand et al. (2007) used estimates of intra-herd variance components and results from cluster analyses for the identification of contract herds. Selected herds were characterized by a high production level, large herd sizes, and an early average age at first calving.

Consequently, in contract herds in Thuringia, electronic database systems were implemented that allow combining of test-day records with health disorders recorded from veterinarians, claw trimmers, and farmers, and the parallel documentation of further effects related to herd management. A system for the direct recording of health traits is imperative for the improvement of the health status in the whole population via breeding strategies. In the past, the main problem regarding the inclusion of health traits in the breeding goal was the lack of appropriate data, and in most 
cases, indirect measurements were used. For example for the improvement of udder health, generally SCC is used as an indicator for breeding on resistance against mastitis. Based on several published results, Heringstad et al. (2000) found only a moderate genetic correlation of 0.60 between SCC and clinical mastitis. The aim of a study by König and Swalve (2006) was to quantify the relative importance of different index traits with respect to selection response for the trait laminitis resistance. Applying selection index theory, they identified a doubling in selection response in laminitis resistance per generation when laminitis observations of 50 daughters per bull were included as index traits instead of using indicator traits. However, the prerequisite for breeding strategies is the direct recording of health traits, which is difficult to realize in the whole population. Mark (2004) gave a detailed review for examples of direct recording of functional or next generation health traits. Some of these suggested traits, especially clinical mastitis, have been recorded in Scandinavia over a period of more than $30 \mathrm{yr}$. Traditionally, Scandinavian countries have a leading position in registration and collection of information about new health traits (Mark, 2004). Health data collected via veterinary systems are integrated into the national electronic database system and used for genetic evaluation (Heringstad et al., 2000). Simianer and König (2002) compared the success of international breeding programs in terms of udder health using data from international genetic evaluations. Genetic gain for udder health was highest for the Scandinavian countries. Additionally, the advantage of direct selection strategies for mastitis on the phenotypic scale was demonstrated via a long-term selection experiment (Heringstad et al., 2007). Beside Scandinavia, udder health monitoring projects also have been established for dual purpose Simmental cows in Austria, and a large amount of data has been used for genetic studies (Koeck et al., 2010a,b). Also in the Netherlands (Windig et al., 2010), substantial data sets for genetic analyses of clinical mastitis in combination with bacteriological characterizations have been used for a multitude of genetic studies.

So far, in Germany, genetic parameters for clinical and subclinical mastitis in combination with pathogenspecific data are only based on small data sets. Based on observations from 400 cows from one farm, Schafberg et al. (2006) estimated heritabilities for Staphylococcus aureus and CNS ranging between 0.03 and 0.09 when applying different statistical models. In the study by Hinrichs et al. (2005), 3,200 cows from 3 different farms in Germany were used to estimate heritabilities for mastitis, and to infer relationships between mastitis and production. Consequently, the aim of the present study was an extension of genetic studies by including further health traits being available from a substantial data set recorded in large-scale contract herds. A further focus was on the estimation of genetic relationships between selected health disorders, SCS, and production traits (protein yield, protein percent, and fat percent), and to study incidences of health disorders during the course of lactation.

\section{MATERIALS AND METHODS}

\section{Data}

Test-day records for protein yield, fat percent, protein percent, and SCC, as well as health disorders for a total of 954 different diagnoses were available from 19,870 Holstein cows kept in 9 large-scale contract herds in the region of Thuringia in the eastern part of Germany. The monthly test-day SCC was log-transformed into test-day SCS to achieve normality and homogeneity of variances using the formulas by Ali and Shook (1980). Data for analyses were recorded from January 2007 over a period of 2 yr. Hence, some cows had observations from 2 different lactations, resulting in 23,873 lactations. Records were from parities 1 to 12 . The number of cows per herd ranged from 616 to 2,800 . Cows were sired by 1,147 different bulls, which implies an average of 17 daughters per sire. From the pool of sires, 47 had more than 50 daughters, 106 sires had 21 to 50 daughters, 146 sires had 11 to 20 daughters, 214 sires had 6 to 10 daughters, and 357 sires had 2 to 5 daughters. The number of animals in the pedigree file was 90,283 , and deepest pedigrees were traced back to founder animals born in 1920 .

Diagnoses were defined according to the recording key developed by Feucker and Staufenbiel (2003). This system for recording diagnoses is based on experiences of and collaborations between veterinarians and farmers, and is mainly used in large-scale farms in the eastern part of Germany. For statistical analyses, 15 health disorders with highest incidences at a lactation level (= proportion of cows with at least 1 treatment during lactation for a particular disease) were extracted and also combined into the following 5 disease categories: claw disorders, mastitis, female fertility, metabolism, and ectoparasites (Table 1).

Most of the individual diseases, defined subcategories, and categories according to Feucker and Staufenbiel (2003) are described in Table 1. Further explanation is needed for lameness, mastitis, ectoparasites, and metabolism. In the description of the recording key, lameness implies a cow being obviously lame due to swellings and injuries at the hocks, hips, and pelvic bones. As such, lameness also belongs to the overall category I: claw disorders, and the subcategory I.3: 
Table 1. Single and combined health disorders (= categories and subcategories) as used in the present study along with their mean incidences

\begin{tabular}{|c|c|c|c|}
\hline Health disorder/category/subcategory & Description of health disorder & \multicolumn{2}{|c|}{ Incidence $^{1}(\%)$} \\
\hline I.1) Subcategory: purulent CD & Including I.1a, I.1b, I.1c & 4.0 & 19.0 \\
\hline I.1a) Sole ulceration & Infection of the corium & 1.5 & 7.4 \\
\hline I.1b) Interdigital phlegmona & Infection of interdigital connective tissue & 0.8 & 5.6 \\
\hline I.2a) Laminitis & Aseptic infection of the corium & 1.1 & 7.6 \\
\hline I.2b) Interdigital hyperplasia & Bead between the inner and outer claw & 0.9 & 4.4 \\
\hline I.2c) White line disease & Separation between sole and wall horn & 0.5 & 2.5 \\
\hline I.3a) Lameness ${ }^{2}$ & Cow is obviously lame ${ }^{2}$ & 2.2 & 7.3 \\
\hline II) Category: mastitis & Including II.1, II.2 & 7.7 & 38.0 \\
\hline II.1) Clinical mastitis & Obvious infection (pain, heat, redness) & 6.7 & 34.6 \\
\hline II.2) Subclinical mastitis ${ }^{2}$ & Increased SCC via Schalm test & 1.1 & 6.5 \\
\hline III.2) Subcategory: ovary & Including III.2a, III.2b, III.2c, III.2d & 7.3 & 31.5 \\
\hline III.2a) Silent estrus & No visible signs of estrus & 1.7 & 9.8 \\
\hline III.2b) Ovarian cysts & Degenerated persistent follicles & 3.5 & 15.7 \\
\hline III.2c) Corpus luteum persistent & Corpus luteum persistent on the ovary & 2.5 & 13.3 \\
\hline IV) Category: metabolism & Ketosis, milk fever, abomasum & 1.0 & 7.8 \\
\hline V) Category: ectoparasites & Ectoparasite infection (e.g., lice, ticks) & 1.5 & 10.6 \\
\hline
\end{tabular}

${ }^{1}$ Incidences: first value $=$ incidences at a test-day level = proportion of diseased cows on a specific test day averaged over all test days; second value $=$ incidences at a lactation level $=$ proportion of cows with at least 1 treatment during lactation for a particular disease.

${ }^{2}$ Detailed explanation in the text of the manuscript.

miscellaneous claw disorders. The category mastitis was divided into clinical and subclinical mastitis. Clinical mastitis implies an obvious infection and a treatment by a veterinarian, whereas subclinical mastitis is based on visual inspections of the California Mastitis Test results (Schalm and Noorlander, 1957) as used by farmers. Due to extremely low incidences of health disorders belonging to the categories IV: ectoparasites and V: metabolism, only categories instead of single traits were used for genetic analyses.

Health disorders were assigned to the nearest official test day of the whole lactation. Hence, repeated measurements for health disorders were official test-day records within lactation by considering in total 199,027 test-day observations for the same trait. Depending on the difference in days between 2 consecutive official test dates, time windows were defined. An example might be the following: the first official test day of a cow is $10 \mathrm{~d}$ after calving, and the second test day is at DIM 42. Hence, the threshold separating these 2 test days is DIM 26. The general interval between 2 consecutive official test days is approximately $30 \mathrm{~d}$. Consequently, also a defined time window (apart from the first window) spans this period of $30 \mathrm{~d}$. On average, the first test day after calving was at DIM 16, the following at DIM 46, and so on. This implies an average of $31 \mathrm{~d}$ for the first interval. The average number of official test days per cow and lactation was 8.3, with a maximum value of 15 . The method as described above for assigning health disorders to official test days resulted for all traits in the same number of repeated measurements per cow. Within the defined time window, repeated measurements for the same health disorder were not taken into account and coded with a 1 , irrespective of the number of entries for this health disorder; otherwise, for a healthy cow, a score of 0 was assigned. At a threshold point dividing 2 consecutive time windows, a minimum period of $5 \mathrm{~d}$ was required to consider a treatment as a new disease case. This period was also used by Hinrichs et al. (2005). An example for health data preparation for statistical analyses is illustrated in Figure 1.

\section{Statistical Models}

Estimation of (co)variance components was done using the computer package Multiple Traits Gibbs Sampling for Animal Models (MTGSAM; Van Tassell and Van Vleck, 1995). A Bayesian approach using Gibbs sampling was applied.

Repeatability models were fitted, with health disorders as binary (threshold) and protein yield, protein 


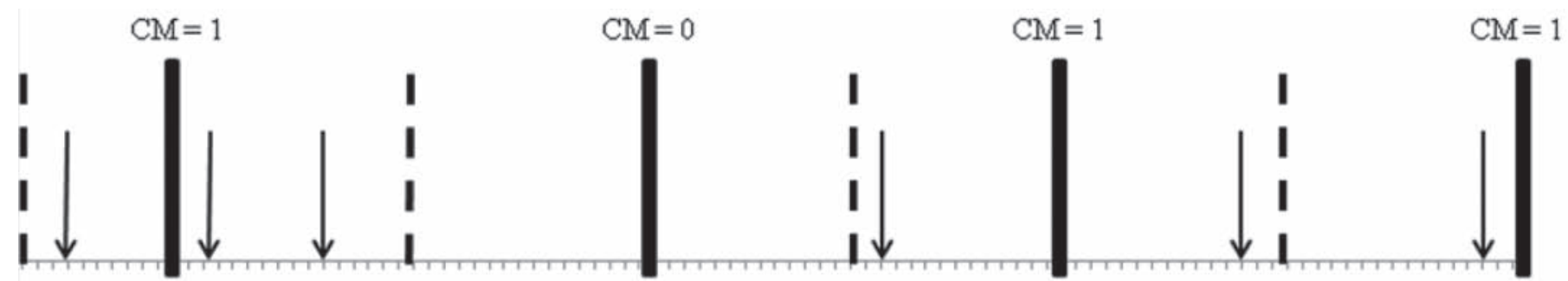

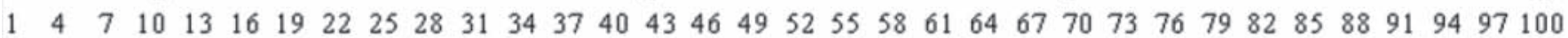

DIM

Figure 1. Example of data preparation for analyses of health disorders for 1 cow. $\mathrm{CM}=$ clinical mastitis; arrows = occurrence of CM; black bars = date of official test days for production traits; dashed lines $=$ thresholds of defined time windows for assigning occurrences of CM to the nearest official test date.

percent, fat percent, and SCS as Gaussian traits. Univariate repeatability models were applied to estimate variance components for all health disorders as specified in Table 1. In matrix notation, the model for a binary trait was

$$
[\mathbf{l}]=[\mathbf{X b}+\mathbf{Z u}+\mathbf{W} \mathbf{p}+\mathbf{e}]
$$

and consequently, for a Gaussian trait,

$$
[\mathbf{y}]=[\mathbf{X} \mathbf{b}+\mathbf{Z u}+\mathbf{W} \mathbf{p}+\mathbf{e}]
$$

where $\mathbf{l}=$ vectors of unobserved liabilities for health disorders from a binary outcome; $\mathbf{y}=$ vectors of observations for test-day production records; $\mathbf{b}=$ vector of fixed effects of herd-test day (HTD), parity, and regressions on DIM using polynomials of order $3 ; \mathbf{u}=$ vector of random additive genetic effects; $\mathbf{p}=$ vector of random permanent environmental effects for cows; $\mathbf{e}$ $=$ vector of random residual effects; and $\mathbf{X}, \mathbf{Z}$, and $\mathbf{W}$ $=$ incidence matrices for $\mathbf{b}, \mathbf{u}$, and $\mathbf{p}$, respectively. The (co)variance structure for random effects was

$$
\operatorname{var}\left[\begin{array}{l}
\mathbf{u} \\
\mathbf{p} \\
\mathbf{e}
\end{array}\right]=\left(\begin{array}{ccc}
\boldsymbol{\sigma}_{\mathrm{g}}^{2} \mathbf{A}_{\mathbf{u}} & \mathbf{0} & \mathbf{0} \\
\mathbf{0} & \boldsymbol{\sigma}_{\mathrm{p}}^{2} & \mathbf{0} \\
\mathbf{0} & \mathbf{0} & \boldsymbol{\sigma}_{\mathrm{e}}^{2}
\end{array}\right),
$$

with $\sigma_{\mathrm{g}}^{2}, \boldsymbol{\sigma}_{\mathrm{p}}^{2}$, and $\boldsymbol{\sigma}_{\mathrm{e}}^{2}$ denoting variances of additive genetic, permanent environmental, and residual effects, respectively; and $\mathbf{A}_{\mathrm{u}}$ is an additive genetic relationship matrix for $\mathrm{u}$ animals in the whole pedigree.

Bivariate repeatability models were applied 1) to estimate covariance components between selected health disorders, 2) to estimate covariance components between selected health disorders and test-day production traits (protein yield, protein percent, fat percent), and
3) to estimate covariance components between selected health disorders and test-day SCS as an indicator trait for mastitis. In the case of a bivariate study including 2 binary health traits, threshold models were applied. Here, the statistical model (repeatability model for 2 traits 1 and 2 in matrix notation) was

$$
\left[\begin{array}{l}
\mathbf{l}_{1} \\
\mathbf{l}_{2}
\end{array}\right]=\left[\begin{array}{l}
\mathbf{X} \mathbf{b}_{1}+\mathbf{Z u}_{1}+\mathbf{W} \mathbf{p}_{1}+\mathbf{e}_{1} \\
\mathbf{X b}_{2}+\mathbf{Z} \mathbf{u}_{2}+\mathbf{W} \mathbf{p}_{2}+\mathbf{e}_{2}
\end{array}\right],
$$

where $\mathbf{l}=$ vectors of unobserved liabilities for health disorders from a binary outcome for traits 1 and 2 . Fixed and random effects were the same as used for the univariate repeatability models. In the case of a bivariate study including 1 binary trait and 1 Gaussian trait, threshold-linear models were applied. Consequently, the statistical model for a binary trait 1 and a Gaussian trait 2 was

$$
\left[\begin{array}{c}
\mathbf{l}_{1} \\
\mathbf{y}_{2}
\end{array}\right]=\left[\begin{array}{l}
\mathbf{X} \mathbf{b}_{1}+\mathbf{Z} \mathbf{u}_{1}+\mathbf{W} \mathbf{p}_{1}+\mathbf{e}_{1} \\
\mathbf{X} \mathbf{b}_{2}+\mathbf{Z} \mathbf{u}_{2}+\mathbf{W} \mathbf{p}_{2}+\mathbf{e}_{2}
\end{array}\right],
$$

where $\mathbf{l}=$ vectors of unobserved liabilities for health disorders from a binary outcome (trait 1), and $\mathbf{y}=$ vectors of observations for test-day production records (trait 2).

The (co)variance structure was as follows:

$$
\operatorname{var}\left[\begin{array}{l}
\mathbf{u} \\
\mathbf{p} \\
\mathbf{e}
\end{array}\right]=\left(\begin{array}{ccc}
\mathbf{G} \otimes \mathbf{A}_{\mathbf{u}} & \mathbf{0} & \mathbf{0} \\
\mathbf{0} & \mathbf{P} \otimes \mathbf{I}_{\mathbf{p}} & \mathbf{0} \\
\mathbf{0} & \mathbf{0} & \mathbf{R} \otimes \mathbf{I}_{\mathbf{R}}
\end{array}\right),
$$

where $\mathbf{G}$ is a $2 \times 2$ additive genetic (co)variance matrix for 1 Gaussian and 1 binary trait, or for 2 binary traits; $\mathbf{P}$ is a $2 \times 2$ permanent environmental covariance matrix for cows in both traits; $\mathbf{I}_{\mathrm{p}}$ is an identity matrix for 
p cows; $\mathbf{R}$ is a $2 \times 2$ residual variance matrix for the 2 traits; $\mathbf{I}_{\mathbf{R}}$ is an identity matrix for $\mathrm{r}$ records; and $\otimes$ is direct matrix product.

Length of burn-in and of the sampling period were assessed by visual inspections of a Gibbs chain of genetic covariances. Based on the visual inspections of trace plots, chain lengths of 250,000 iterations were used, and first 50,000 rounds were discarded as burn-in. Hence, posterior means and posterior standard deviations for fixed and random effects as well as for (co)variance components were calculated from 200,000 samples. Independent proper uniform priors were assigned to each of the elements of vectors for fixed and random effects. The residual variance of the binary trait was set to 1 .

\section{RESULTS AND DISCUSSION}

\section{Incidences of Health Disorders}

Pronounced differences in mean incidences of analyzed health disorders (i.e., the proportion of cows with at least 1 treatment during lactation for a particular disease), were found when comparing the 9 contract herds (Figure 2). Apart from ectoparasites, all diseases were found or recorded in all farms. In herd 1, incidences for ectoparasites were extremely high, with a value of $55.9 \%$, but no incidences were observed in herds $2,3,4$, and 5. This may be the causal consequence of an infection. This is especially the case with the expeditious spread of cattle lichen within a closed environment of a dairy cattle herd. Incidences for some health disorders were at a fairly low level. For example, the category metabolism had a mean occurrence of only $0.2 \%$ in herd 3. Results from herd management software revealed totally different management and feeding strategies between farms, and a multitude of interactions exists. Koenig et al. (2005) investigated claw disorders from large-scale dairy farms and they tried to identify factors causing such substantial differences in mean incidences between farms. However, their attempt based on information related to feeding and management as collected in herd management programs was not successful. For example, for the best and the worst herd regarding sole ulceration, identical feeding strategies, husbandry systems, and floor surfaces were identified. Hence, general conclusions for improving environments or farm management to improve dairy cattle health cannot be drawn.

Mean incidences of health disorders by parity (i.e., the proportion of cows with at least 1 treatment during lactation for a particular disease), are shown in Table 2. Generally, an increase of incidences was associated with increasing lactation number as found by Heringstad et al. (2005) for a multitude of health traits. In our study, when summarizing incidences from all health disorders, incidences increased from $72.5 \%$ in parity 1 to $79.9 \%$ in parity 7 . Corresponding values at a test-day level (i.e., the proportion of diseased cows at a specific test day averaged over all test days) were 22.9 and $33.3 \%$ in parity 1 and 2, respectively. For digital dermatitis, incidences decreased with increasing lactation number. This is in line with Koenig et al. (2005) who found

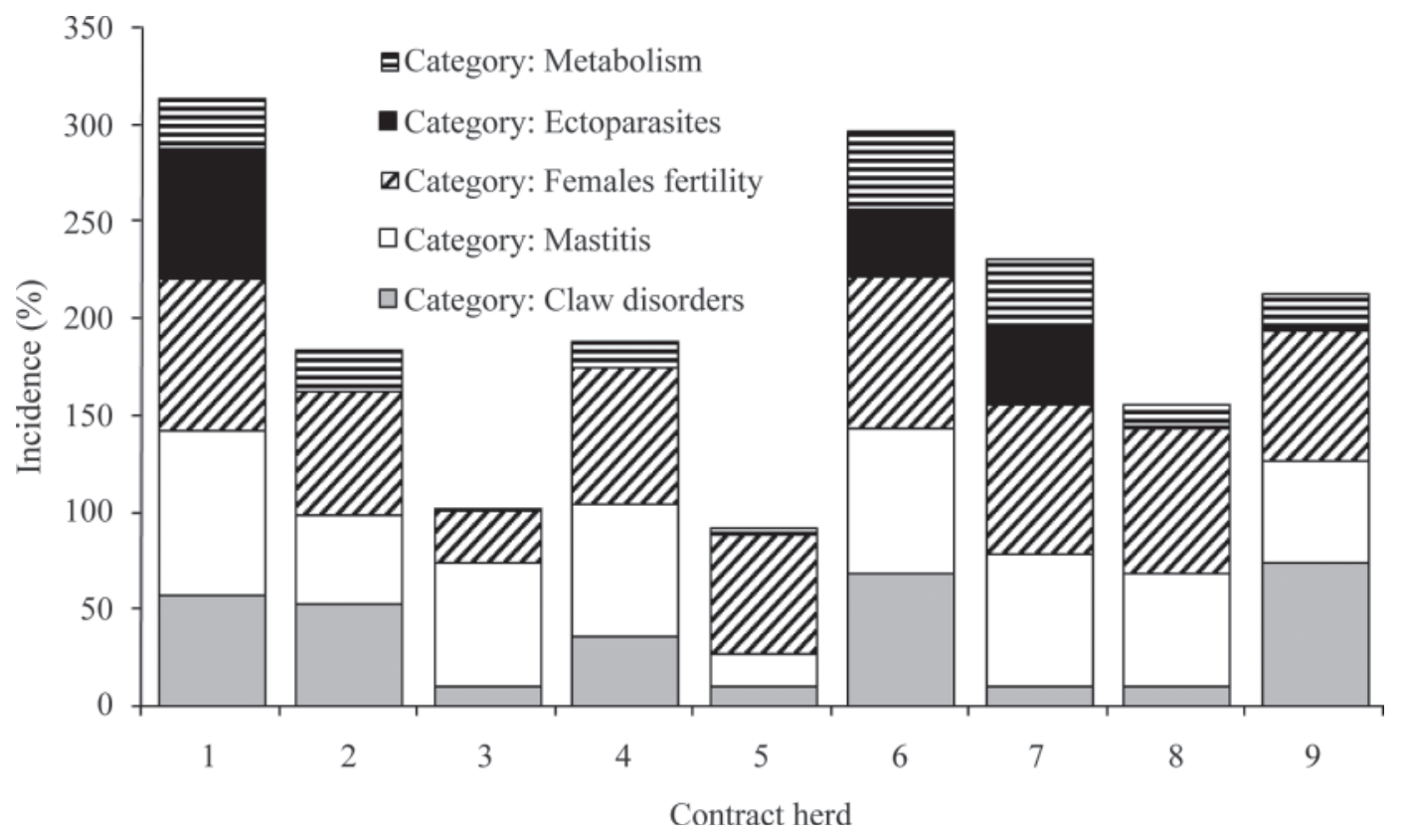

Figure 2. Mean incidences of health disorders in participating contract herds. 
Table 2. Incidences of health disorders (\%) by parity at a lactation level (= proportion of cows with at least 1 treatment during lactation for a particular disease)

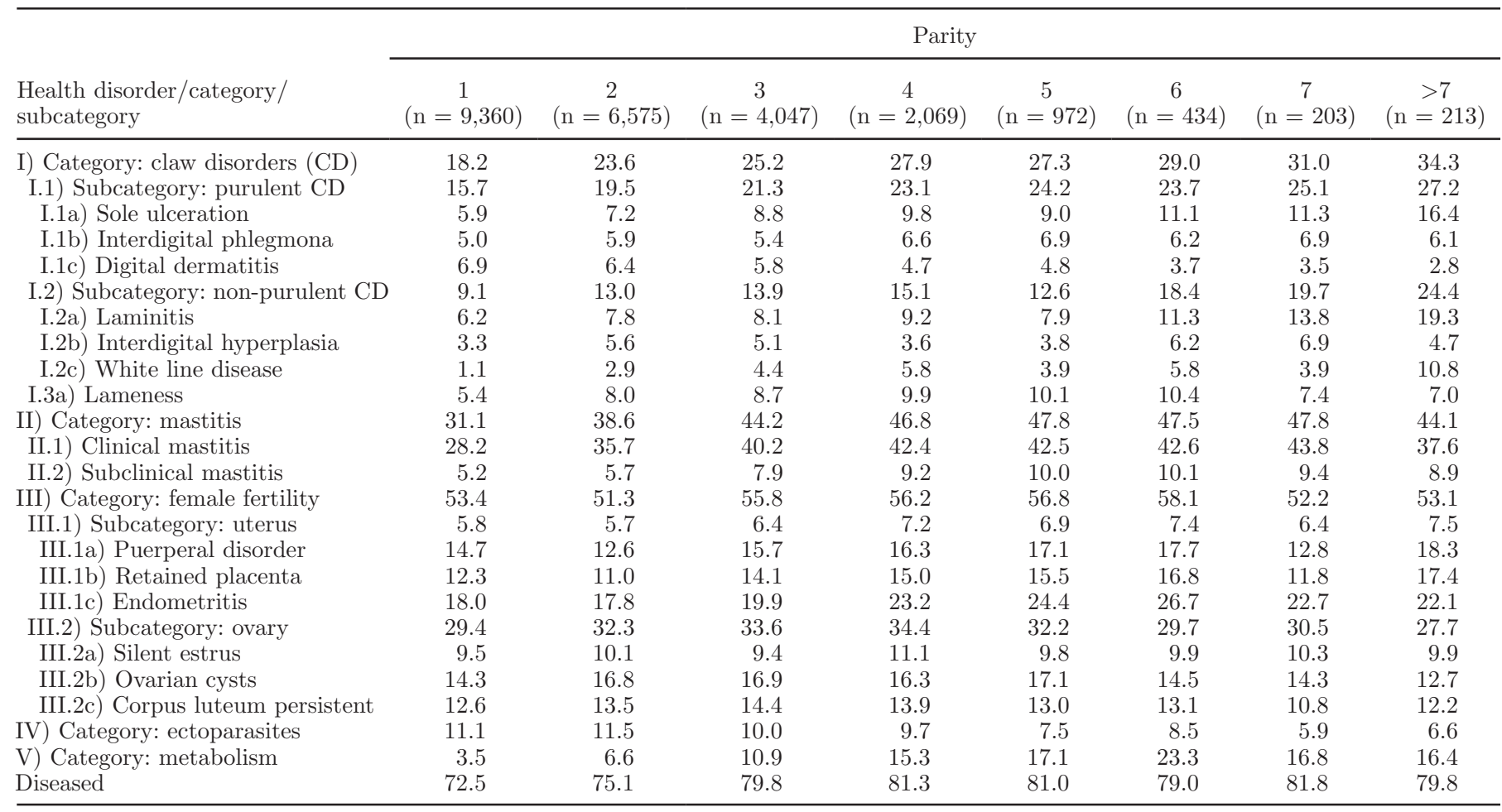

that heifers' liability to digital dermatitis was higher than in adult cows. Some type of resistance against bacteria causing digital dermatitis can be anticipated and, of course, an effect of selection exists. Large-scale dairy farming in the eastern part of Germany is characterized by high selection pressure in first lactation, and consequently, replacement rates are at a high level (Hufe, 2003).

Longitudinal structure of health data was used to analyze incidences of health disorders by lactation stage at specific test days (Figures 3, 4, and 5). For the claw disorders interdigital phlegmona, interdigital hyperplasia, and digital dermatitis (Figure 3), for the female fertility traits puerperal disorders, endometritis, and retained placenta (Figure 4), and for mastitis and metabolism (Figure 5), incidences were highest directly after calving. A further incidence peak was observed in the time interval between test-day 2 and test-day 5 for ovarian cysts, corpus luteum persistent, and silent estrus (Figure 4). The distribution of incidences seems logical, as the metabolism of the dairy cow is exposed to physiological stress with the onset of a new lactation due to high milk yield. Collard et al. (2000) identified high milk yield within the first third of lactation as a major reason for health problems. They concluded that metabolic stress occurs when energy output is higher than energy input, inevitably resulting in too quick a mobilization of body fat reserves. Similar results with the highest incidences in the first third of lactation are reported by Fleischer et al. (2001) for retained placenta, metritis, ovarian cysts, mastitis, claw diseases, milk fever, ketosis, and displaced abomasum, and by Harder et al. (2006) for fertility disorders in German Holstein cows. In contrast to all other health disorders, incidences for infections with ectoparasites slightly increased from $1.1 \%$ at test-day 1 to $4.3 \%$ at the end of lactation (Figure 5). Especially for heifers that have to be integrated into the cow herd, some time is required from the infection with ectoparasites in the new environment to the time point where farmers detect infestations.

\section{Variance Ratios for Disorders}

Posterior means and posterior standard deviations of heritabilities, variance ratios of the permanent environmental component, and repeatabilities for health disorders are given in Table 3. Among all traits analyzed, the heritability estimate with a value of 0.22 was highest for interdigital hyperplasia. A relatively strong genetic background for interdigital hyperplasia was found in previous German studies, which estimated heritabilities of claw disorders (e.g., $\mathrm{h}^{2}=0.28$ for Holstein cows; Burmester, 2005). Among all claw and foot disorders 


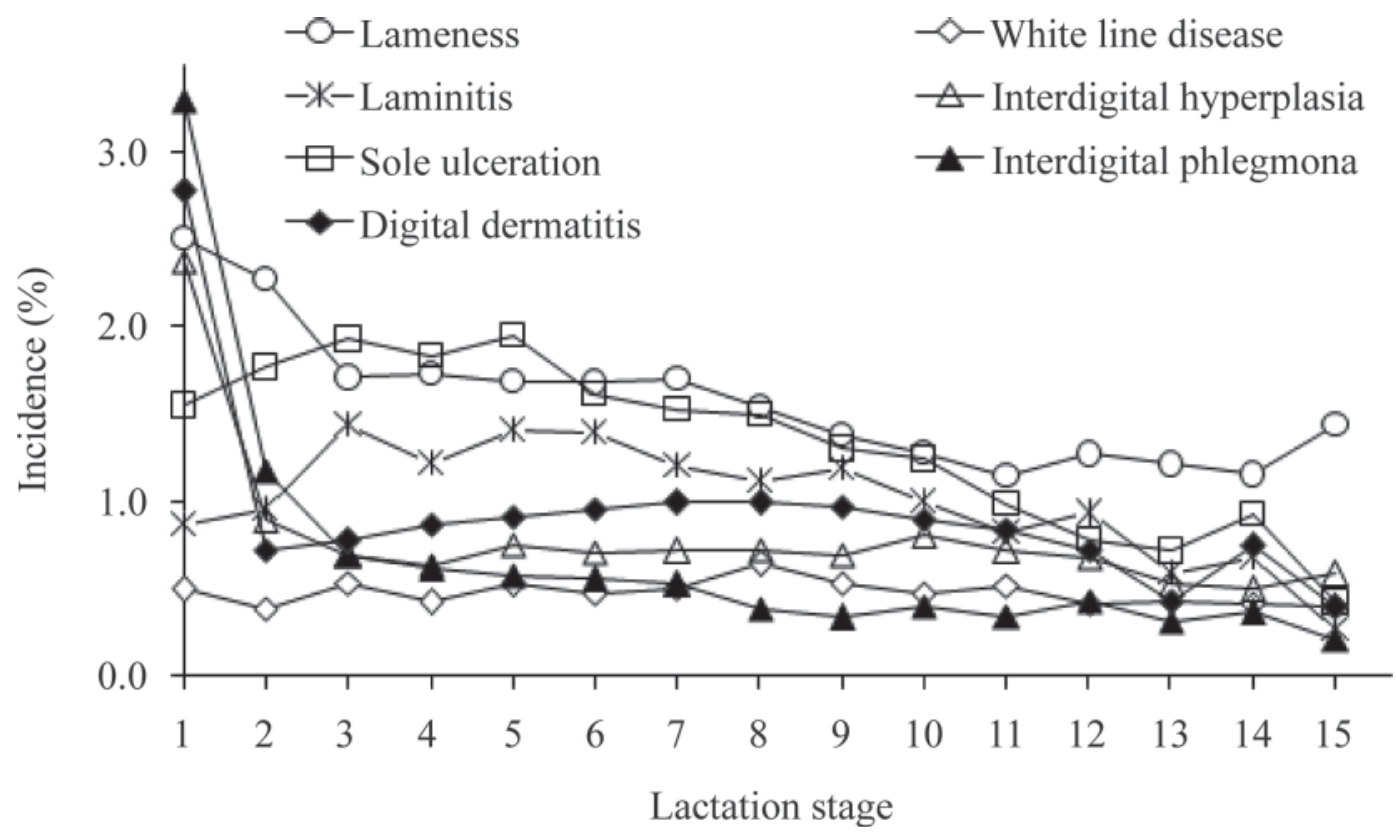

Figure 3. Incidences of diseases (diseases belonging to category I = claw disorders) by lactation stage (assigned numbers for lactation stage indicate the official test days after calving).

in the study by Koenig et al. (2005), heritability was also highest for interdigital hyperplasia, but overall at a lower level (0.12). The permanent environmental component for interdigital hyperplasia in the present study was relatively high, resulting in a repeatability of 0.50 . Hence, occurrence of interdigital hyperplasia directly after calving is associated with a risk of further incidences during lactation. Heritabilities and repeatabilities of remaining claw disorders in the present study were substantially lower. Heritabilities ranged between 0.05 (laminitis) and 0.09 (digital dermatitis), and repeatabilities between 0.06 (laminitis) and 0.32 (sole ulceration). Results for heritabilities are comparable to estimates from previous studies conducted

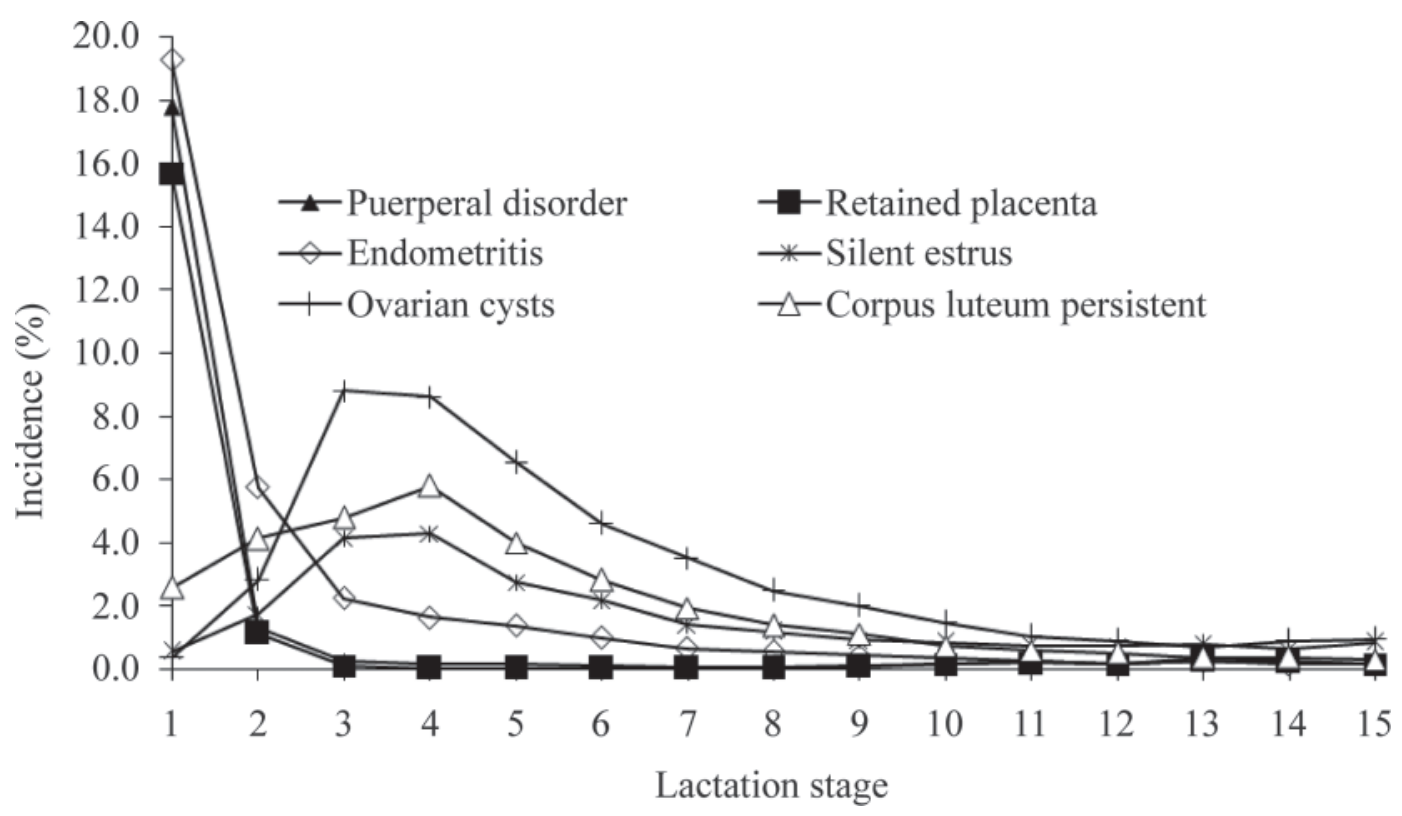

Figure 4. Incidences of diseases (diseases belonging to category III = female fertility) by lactation stage (assigned numbers for lactation stage indicate the official test days after calving). 


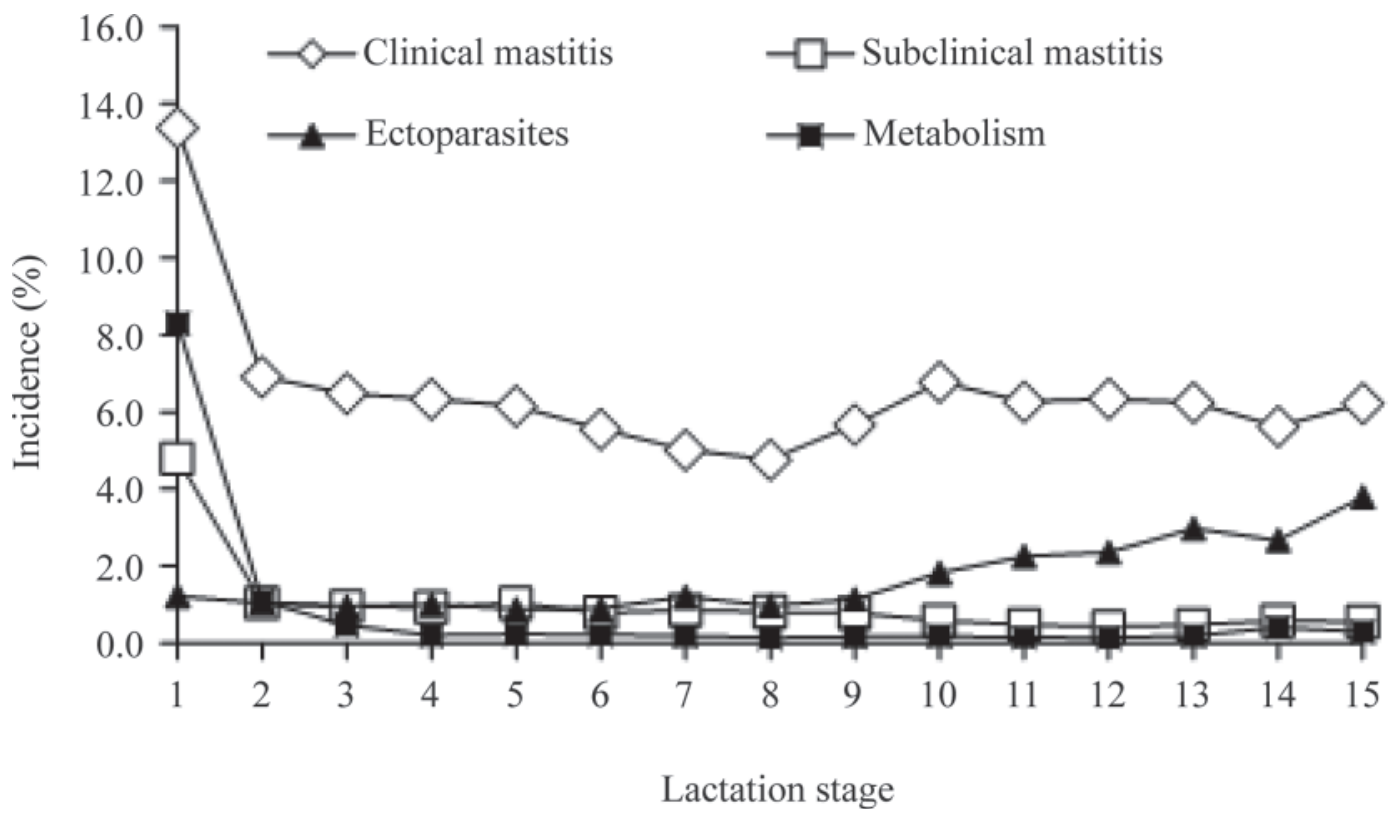

Figure 5. Incidences of diseases (diseases belonging to category II = mastitis, category IV = metabolism, and category $\mathrm{V}=$ ectoparasites) by lactation stage (assigned numbers for lactation stage indicate the official test days after calving).

in the eastern part of Germany (Koenig et al., 2005; König et al., 2008).

Combining all cases of mastitis, posterior heritability was 0.06 (Table 3). Heritability was higher for clinical than for subclinical mastitis (0.06 and 0.03, respectively). Substantially higher permanent environmental variances for subclinical mastitis resulted in higher repeatabilities compared with clinical mastitis. Hence, a major non-genetic component must exist causing repeated infections. For studying the genetic background of mastitis in detail, some other studies focused on specific pathogens (e.g., de Haas et al., 2008). Gen-

Table 3. Posterior means and posterior standard deviations for heritabilities $\left(\mathrm{h}^{2}\right)$, ratios of permanent environmental variances $\left(\mathrm{pe} \mathrm{e}^{2}\right.$ ), and repeatabilities $\left(r^{2}\right)$ for single diagnoses and categories of health disorders

\begin{tabular}{|c|c|c|c|c|c|c|}
\hline Health disorder/category/subcategory & $\mathrm{h}^{2}$ & $\mathrm{SD}\left(\mathrm{h}^{2}\right)$ & $\mathrm{pe}^{2}$ & $\mathrm{SD}\left(\mathrm{pe}^{2}\right)$ & $\mathrm{r}^{2}$ & $\mathrm{SD}\left(\mathrm{r}^{2}\right)$ \\
\hline I.1) Subcategory: purulent CD & 0.05 & 0.01 & 0.15 & 0.01 & 0.20 & 0.01 \\
\hline I.1a) Sole ulceration & 0.07 & 0.02 & 0.24 & 0.03 & 0.32 & 0.01 \\
\hline I.1c) Digital dermatitis & 0.09 & 0.02 & 0.13 & 0.02 & 0.23 & 0.02 \\
\hline I.2) Subcategory: non-purulent CD & 0.07 & 0.01 & 0.14 & 0.01 & 0.20 & 0.01 \\
\hline I.2a) Laminitis & 0.06 & 0.01 & 0.00 & 0.00 & 0.06 & 0.01 \\
\hline I.3a) Lameness & 0.09 & 0.02 & 0.22 & 0.02 & 0.30 & 0.01 \\
\hline II) Category: mastitis & 0.06 & 0.01 & 0.10 & 0.01 & 0.16 & 0.01 \\
\hline II.1) Clinical mastitis & 0.06 & 0.01 & 0.09 & 0.01 & 0.15 & 0.01 \\
\hline II.2) Subclinical mastitis & 0.03 & 0.01 & 0.23 & 0.02 & 0.27 & 0.02 \\
\hline III) Category: female fertility & 0.04 & 0.01 & 0.17 & 0.01 & 0.21 & 0.01 \\
\hline III.1) Subcategory: uterus & 0.01 & 0.01 & 0.09 & 0.03 & 0.10 & 0.03 \\
\hline III.1a) Puerperal disorder & 0.03 & 0.01 & 0.06 & 0.02 & 0.09 & 0.02 \\
\hline III.2c) Corpus luteum persistent & 0.04 & 0.01 & 0.12 & 0.01 & 0.16 & 0.01 \\
\hline IV) Category: ectoparasites & 0.00 & 0.00 & 0.00 & 0.00 & 0.00 & 0.00 \\
\hline V) Category: metabolism & 0.05 & 0.01 & 0.18 & 0.02 & 0.23 & 0.02 \\
\hline Diseased & 0.04 & 0.01 & 0.08 & 0.01 & 0.12 & 0.00 \\
\hline
\end{tabular}


erally for the German situation, such data has to be interpreted with caution. Usually, only a small fraction of cows with clinical or subclinical mastitis is used for identifying specific pathogens. This implies that cows categorized for clinical mastitis are scored healthy with regard to specific pathogens due to lacking laboratory investigations. Utilizing those data for genetic studies would result in biased estimates of genetic parameters. Schafberg et al. (2006) only used data from 1 farm that has implemented a scheme for analyzing specific major pathogens of all cows. However, for a reliable national genetic evaluation, those traits have to be selected that can be easily and identically recorded in all participating contract herds. Examples for a successful implementation of such suitable traits are demonstrated by Heringstad et al. (2007) via analyses of selection experiments conducted in Norway. Especially for clinical mastitis, Heringstad et al. (2007) impressively showed the possibilities of improving the status of udder health by consistently using sires with favorable EBV for clinical mastitis. Our heritability estimates for clinical mastitis are in line with results from the recently established and comparable health monitoring project in Austria (Koeck et al., 2010a). These authors also used threshold methodology in a Bayesian framework and heritabilities on the underlying liability scale ranged from 0.02 to 0.06 .

Posterior heritabilities with values ranging between 0.01 and 0.06 for the category female fertility and belonging subcategories and diseases (Table 3) are in the range reported in the literature (e.g., Zwald et al., 2006). Clustering fertility disorders into categories or analyzing single diseases revealed heritabilities of roughly the same magnitude. In some cases, heritabilities from subcategories or categories were marginally higher (e.g., $h^{2}=0.05$ for the subcategory ovary compared with $\mathrm{h}^{2}=0.04$ for corpus luteum persistent). In contrast, when analyzing the subcategory uterus, heritability was at the overall lowest level, with a value of 0.01. Diseases included in the category female fertility are strongly associated with a cow's recovery after calving, which has a further effect on the interval from calving to first service. Traditionally in genetic evaluations, only fertility traits related to the success of an insemination have been used (e.g., nonreturn rates after $56 \mathrm{~d}$ or after $90 \mathrm{~d}$ ). Knowledge of diseases such as retained placenta or endometritis will contribute to a deeper understanding of the physiological mechanisms of female fertility. Hence, genetic parameters of single fertility disorders can be used to develop new fertility indices. Interestingly, also for female fertility disorders, values for ratios of permanent environmental variances were substantially higher than estimates of heritabilities. This was found for all diseases summarized in the category female fertility apart from retained placenta. This finding can easily be explained, because retained placenta only occurs directly after calving.

Lowest heritabilities among all health disorders were found for ectoparasites (Table 3). Brown et al. (1992) estimated genetic parameters for ectoparasites in beef cattle by applying different statistical models, and heritability for the resistance against horn flies ranged from 0.59 to 0.78 . In Zebu cattle, the heritability estimate for resistance against the tick Boophilus microplus was 0.27 (Andrade et al., 1998). To our knowledge, no studies exist addressing heritabilities for ectoparasite-related diseases such as acrodermatitis, lichen, or scabies in Holstein cows in Europe.

Health disorders belonging to the category metabolism (i.e., ketosis, milk fever, and displaced abomasum) had higher incidences in some other studies (e.g., Heringstad et al., 2005). Consequently, they were analyzed separately in other studies when estimating genetic parameters. In large-scale farms in east Germany, König et al. (2005) identified a variety of management tools, and one of these tools is feeding of a TMR, which is not practical on a small farm. In general, feeding of a TMR is associated with an increase of DMI (e.g., Bargo et al., 2002), and consequently, decreases metabolic diseases in early lactation. Heritability for the category metabolism, with a value of 0.05 , was relatively low (Table 3 ), but permanent environmental variance $(0.18)$ and repeatability $(0.23)$ were substantially higher. Estimation of genetic parameters for health disorders of the complex metabolism (e.g., displaced abomasum, ketosis, and milk fever) was the topic of a limited number of studies. For displaced abomasum, a wide range of heritabilities [i.e., 0.08 Abdel-Azim et al. (2005), 0.15 (Zwald et al., 2004), 0.28 (Uribe et al., 1995), and 0.51 (Wolf et al., 2001)] has been reported. The latter study estimated heritabilities for binary traits by applying linear models and transforming them to the underlying liability scale according to the formula by Dempster and Lerner (1950). Considering only ketosis, heritability estimates based on threshold methodology were almost identical [i.e., 0.08 (Uribe et al., 1995), 0.06 (Zwald et al., 2004), and 0.11 (Frigo et al., 2010)]. Heringstad et al. (2005) applied threshold methodology in a Bayesian framework to estimate heritabilities for ketosis and milk fever in parities 1, 2, and 3. Estimates of heritability of liability for ketosis ranged from 0.14 to 0.16 , and for milk fever from 0.09 to 0.13 .

\section{Correlations Between Selected Health Disorders}

Due to the multitude of pairwise combinations, estimation of genetic covariances and correlations has focused on those diseases characterized by highest 
incidences in combination with highest heritabilities within subcategories of the overall categories claw disorders, female fertility, and mastitis as defined in Table 1. Selected diseases belonging to claw disorders of the subcategories I.1, I.2, and I.3 were digital dermatitis, interdigital hyperplasia, and lameness, respectively. With regard to female fertility, endometritis was used from subcategory III.1, and ovarian cysts from subcategory III.2. Within the overall category mastitis, no subcategories were defined, and clinical mastitis was used in bivariate studies.

Correlations for the additive-genetic, permanent environmental, residual, and phenotypic components among selected health disorders are given in Table 4. Generally, genetic correlations were low and close to zero. Koenig et al. (2005) found positive genetic correlations among claw disorders, and between claw disorders and indicator traits for mastitis within a moderate range. They concluded that health problems seem to appear in clusters, meaning that a cow being susceptible to any disease has an increased genetic risk to show another disease, too. As expected, in most cases, genetic correlations between traits belonging to the same disease category (e.g., between interdigital hyperplasia and dermatitis digitalis, or between endometritis and ovarian cysts) were slightly higher than correlations between traits from different categories.

When correlating clinical mastitis with ovarian cysts and endometritis, correlations were close to 0 (Table 4). Hence, we found no direct effect of the status of udder health on incidences of ovarian cysts and endometritis, and vice versa. Generally, correlations among health disorders from different categories were at a low level, and following these results, it would be difficult to improve all health traits in the German Holstein population simultaneously via breeding strategies. In contrast, in a selection experiment with Norwegian Red cows, it was shown that selection against mastitis leads to a favorable correlated selection response in ketosis and retained placenta (Heringstad et al., 2007).

\section{Correlations Between Selected Health Disorders and Production}

Correlations between selected health disorders and test-day records for protein yield, protein percent, and fat percent are shown in Table 5. We found genetically antagonistic relationships between clinical mastitis and protein yield (0.29), and between ovarian cysts and protein yield (0.57; Table 4). Hooijer et al. (2001) used 305-d lactation yields, and genetic correlations with ovarian cysts were $0.35,0.38$, and 0.44 for milk, fat, and protein yield, respectively. Remaining genetic correlations between health disorders and protein yield in our study were close to 0. Apart from ovarian cysts with a value of 0.20 , phenotypic correlations between health disorders and protein yield were at a low, negative level, ranging from -0.13 (lameness) to -0.03 (endometritis). A broad variety of definitions of traits and of estimates exists for associations between production traits and health disorders on the phenotypic scale. Some authors used 305-d lactation yields, and they found an increase in incidences of health disorders with increasing milk yield (i.e., Fleischer et al., 2001). Other authors used test-day production records from the beginning of lactation and, in most cases, higher

Table 4. Posterior means and posterior standard deviations for genetic $\left(r_{g}\right)$, permanent environmental $\left(r_{p e}\right)$, residual $\left(r_{e}\right)$, and phenotypic $\left(r_{p}\right)$ correlations among selected health disorders

\begin{tabular}{|c|c|c|c|c|c|c|c|c|}
\hline Health disorder & $\mathrm{r}_{\mathrm{g}}$ & $\mathrm{SD}\left(\mathrm{r}_{\mathrm{g}}\right)$ & $\mathrm{r}_{\mathrm{pe}}$ & $\mathrm{SD}\left(\mathrm{r}_{\mathrm{pe}}\right)$ & $\mathrm{r}_{\mathrm{e}}$ & $\mathrm{SD}\left(\mathrm{r}_{\mathrm{e}}\right)$ & $\mathrm{r}_{\mathrm{p}}$ & $\mathrm{SD}\left(\mathrm{r}_{\mathrm{p}}\right)$ \\
\hline \multicolumn{9}{|l|}{ Lameness } \\
\hline Interdigital hyperplasia & 0.04 & 0.02 & 0.04 & 0.02 & 0.06 & 0.00 & 0.06 & 0.00 \\
\hline Digital dermatitis & 0.01 & 0.03 & 0.00 & 0.02 & 0.01 & 0.00 & 0.01 & 0.00 \\
\hline Endometritis & 0.01 & 0.04 & -0.01 & 0.02 & 0.02 & 0.00 & 0.02 & 0.00 \\
\hline Ovarian cysts & 0.11 & 0.04 & 0.13 & 0.02 & 0.03 & 0.00 & 0.04 & 0.00 \\
\hline \multicolumn{9}{|l|}{ Interdigital hyperplasia } \\
\hline Ovarian cysts & 0.01 & 0.03 & 0.00 & 0.02 & 0.00 & 0.00 & 0.00 & 0.00 \\
\hline \multicolumn{9}{|l|}{ Digital dermatitis } \\
\hline Clinical mastitis & -0.01 & 0.03 & -0.01 & 0.03 & 0.00 & 0.00 & 0.00 & 0.00 \\
\hline Endometritis & 0.00 & 0.03 & 0.01 & 0.02 & 0.02 & 0.00 & 0.02 & 0.00 \\
\hline Ovarian cysts & -0.01 & 0.03 & 0.00 & 0.02 & 0.00 & 0.00 & 0.00 & 0.00 \\
\hline \multicolumn{9}{|l|}{ Clinical mastitis } \\
\hline
\end{tabular}


milk yield was associated with a higher risk of an infection in the ongoing lactation (e.g., Koenig et al., 2005). However, the same authors mentioned the aspect that only healthy cows can produce a high milk yield, and they suggested the application of recursive or simultaneous models (Gianola and Sorensen, 2004) to account for feedback situations. Including claw disorders as a binary and milk yield as a Gaussian trait, recursive models have been applied by König et al. (2008). On the first pathway, increased incidences of claw disorders were due to increasing milk yield. The recursive situation was described via a second path, such that an infection decreased milk yield in the ongoing lactation. Apart from protein percent and endometritis with a value of -0.31 , genetic correlations between health disorders and fat percent or protein percent were close to 0 (Table 5).

\section{Correlations Between Selected Health Disorders and One Indicator Trait (SCS)}

Correlations between selected health disorders and the udder health indicator trait SCS are shown in Table 5. Somatic cell score has a long tradition in dairy cattle breeding programs for general use in national and inter- national genetic evaluations. In agreement with other studies (e.g., de Haas et al., 2002), the genetic correlation with a value of 0.69 between clinical mastitis and SCS was at a moderate level. However, the use of the indicator trait SCS was a valuable tool for improving udder health by breeding. Additional gain is possible when focusing on direct selection strategies, but it is always a challenge to get a substantial amount of accurate health data. de Haas et al. (2002) applied selection index calculations and used relatively high economic weights for SCS, but they found that selection strategies based on indicator traits are not efficient enough to decrease incidences of some major pathogens.

The phenotypic correlation between clinical mastitis and SCS in our study with a value of 0.29 was even lower than the genetic correlation. Critical arguments also exist from a veterinary point of view when breeding on low SCS. Kehrli and Shuster (1994) argued that cows with extremely low SCS might be more susceptible to clinical mastitis due to an insufficient immune response.

An increasing number of studies have investigated associations between udder health and female fertility. On the phenotypic scale, chronically diseased cows over the whole lactation and cows with a SCC above 400,000,

Table 5. Posterior means and posterior standard deviations for genetic $\left(\mathrm{r}_{\mathrm{g}}\right)$, permanent environmental $\left(\mathrm{r}_{\mathrm{pe}}\right)$, residual $\left(\mathrm{r}_{\mathrm{e}}\right)$, and phenotypic $\left(\mathrm{r}_{\mathrm{p}}\right)$ correlations between selected diseases with production traits (protein yield, protein percent, fat percent) and with 1 indicator trait (SCS)

\begin{tabular}{|c|c|c|c|c|c|c|c|c|}
\hline Item & $r_{g}$ & $\mathrm{SD}\left(\mathrm{r}_{\mathrm{g}}\right)$ & $\mathrm{r}_{\mathrm{pe}}$ & $\mathrm{SD}\left(\mathrm{r}_{\mathrm{pe}}\right)$ & $\mathrm{r}_{\mathrm{e}}$ & $\mathrm{SD}\left(\mathrm{r}_{\mathrm{e}}\right)$ & $r_{p}$ & $\mathrm{SD}\left(\mathrm{r}_{\mathrm{p}}\right)$ \\
\hline \multicolumn{9}{|l|}{ Lameness } \\
\hline Protein yield & -0.08 & 0.12 & -0.05 & 0.05 & -0.17 & 0.01 & -0.13 & 0.01 \\
\hline Protein \% & -0.02 & 0.11 & -0.12 & 0.09 & -0.01 & 0.00 & -0.03 & 0.01 \\
\hline SCS & 0.23 & 0.12 & -0.05 & 0.05 & 0.01 & 0.01 & 0.01 & 0.01 \\
\hline \multicolumn{9}{|c|}{ Interdigital hyperplasia } \\
\hline Protein yield & -0.06 & 0.11 & -0.20 & 0.07 & -0.07 & 0.02 & -0.10 & 0.02 \\
\hline \multicolumn{9}{|c|}{ Digital dermatitis } \\
\hline Protein yield & -0.11 & 0.14 & -0.02 & 0.09 & -0.05 & 0.01 & -0.05 & 0.02 \\
\hline Protein \% & 0.05 & 0.11 & -0.02 & 0.14 & 0.00 & 0.00 & 0.01 & 0.01 \\
\hline Fat $\%$ & -0.01 & 0.11 & 0.08 & 0.12 & 0.02 & 0.01 & 0.02 & 0.01 \\
\hline SCS & -0.14 & 0.13 & -0.01 & 0.07 & 0.00 & 0.01 & -0.02 & 0.01 \\
\hline \multicolumn{9}{|l|}{ Clinical mastitis } \\
\hline Protein yield & 0.09 & 0.15 & 0.06 & 0.05 & -0.09 & 0.01 & -0.03 & 0.01 \\
\hline Protein \% & -0.31 & 0.10 & 0.10 & 0.07 & 0.00 & 0.00 & -0.02 & 0.01 \\
\hline Fat $\%$ & 0.03 & 0.09 & -0.02 & 0.06 & 0.02 & 0.01 & 0.01 & 0.01 \\
\hline SCS & -0.04 & 0.12 & 0.01 & 0.04 & 0.00 & 0.01 & 0.00 & 0.01 \\
\hline \multicolumn{9}{|l|}{ Ovarian cysts } \\
\hline Protein yield & 0.57 & 0.08 & 0.32 & 0.03 & 0.08 & 0.01 & 0.20 & 0.01 \\
\hline Protein \% & -0.16 & 0.09 & -0.05 & 0.06 & 0.00 & 0.00 & -0.02 & 0.01 \\
\hline Fat $\%$ & -0.01 & 0.09 & -0.06 & 0.06 & -0.01 & 0.01 & -0.02 & 0.01 \\
\hline SCS & 0.05 & 0.11 & -0.01 & 0.03 & 0.00 & 0.01 & 0.00 & 0.01 \\
\hline
\end{tabular}


measured at the first test day after an insemination, showed about $4 \%$ lower pregnancy rates compared with cows having SCC values below 150,000 (König et al., 2006). Schrick et al. (2001) found longer intervals from calving to successful inseminations and an increasing number of inseminations with higher incidences of clinical and subclinical mastitis. Lower pregnancy rates after mastitis were also reported (e.g., by Santos et al., 2004). Focusing on specific diseases related to the female fertility category, as done in our study, only partly describes those associations. The genetic correlation between ovarian cysts and SCS was 0.05, and also close to 0 between endometritis and SCS (Table 4). Also phenotypic correlations were close to 0 .

\section{Assumptions and Limitations of Statistical Modeling}

Following the results of the present study, it can be stated that the applied repeatability model is also useful to estimate genetic parameters for health disorders with low incidences, or for health disorders that are only relevant early in lactation (e.g., retained placenta or metabolic disorders).

For verification of genetic parameters for such traits that are characterized by a limited number of treatments in the middle and at the end of lactation, a relatively simple univariate lactation model was applied. Fixed effects were the same compared with the repeatability model, but without modeling a random permanent environment component. Only the first 100 $\mathrm{d}$ after calving were considered. If the respective health disorder appeared, the cow was scored with a 1, and otherwise with a 0 . Heritabilities were in line with estimates from the univariate repeatability model: 0.04 for the category female fertility, 0.01 for the subcategory uterus, 0.04 for puerperal disorders, 0.05 for retained placenta, and 0.05 for endometritis.

Alternative models for such types of data from onfarm management software have been suggested by Zwald et al. (2006), who divided the lactation in several segments as a base for a multi-trait model. A similar, multivariate model was also applied by Heringstad et al. (2004). Further extensions could be the application of random regression models for binary traits as done by Tsuruta et al. (2009) for conception rate. However, such sophisticated modeling that allows a variation of genetic parameters over DIM implies the availability of a substantially larger data set compared with the data used in the present study.

\section{CONCLUSIONS}

Contract herds for dairy cattle have been implemented on large-scale farms in Thuringia with the primary goal to record new functional health traits for genetic evaluation. The electronic recording database was developed in a way that both farmers and veterinarians could handle such a system very easily. Based on reliable incidences and estimates of genetic parameters for health disorders as found in the present study, we recommend general use of these data for official genetic evaluation. Heritabilities for health disorders were generally lower compared with estimates from previous studies conducted in Germany when data was obtained from research stations or planned experiments, but in line with comparable field studies from Scandinavia and Austria. We also found that grouping related diseases into disease categories does not necessarily imply higher heritabilities or higher additive genetic variances, but a focus for practical applications should be on those traits or clusters of traits that are characterized by moderate incidences and that are relevant for dairy cattle farmers. Incidences, heritabilities, variances, and correlations from the present study are essential prerequisites for the next step (i.e., setting up the most appropriate breeding goal and the evaluation of breeding program designs).

\section{ACKNOWLEDGMENTS}

This study was conducted on dairy cattle farms belonging to the breeding organization Landesverband Thüringer Rinderzüchter (LTR). The authors thank LTR for establishing a system for collecting health data and for their long-standing technical support.

\section{REFERENCES}

Abdel-Azim, G. A., A. E. Freeman, M. E. Kehrli Jr., S. C. Kelm, J. L. Burton, A. L. Kuck, and S. Schnell. 2005. Genetic basis and risk factors for infectious and noninfectious diseases in US Holsteins. I. Estimation of genetic parameters for single diseases and general health. J. Dairy Sci. 88:1199-1207.

Ali, A. K. A., and G. E. Shook. 1980. An optimum transformation for somatic cell concentration in milk. J. Dairy Sci. 63:487-490.

Andrade, A. B. F., R. G. Silva, and A. J. Costa. 1998. Genetic and environmental aspects of the resistance of Zebu cattle to the tick Boophilus microplus. Pages 339-342 in Proc. 6th World Congr. Genet. Appl. Livest. Prod., Armidale, Australia. University of New England, Armidale, Australia.

Bargo, F., L. D. Muller, J. E. Delahoy, and T. W. Cassidy. 2002. Performance of high producing dairy cows with three different feeding systems combining pasture and total mixed rations. J. Dairy Sci. 85:2948-2963.

Brown, A. H., C. D. Steelman, Z. B. Johnson, C. F. Rosenkrans, and T. M. Brasuell. 1992. Estimates of repeatability and heritability of horn fly resistance in beef cattle. J. Anim. Sci. 70:1375-1381.

Burmester, J. 2005. Analyse von Daten aus dem Managementprogramm für Klauenpfleger mittels Schwellenwertmodellen. Msc Thesis. University of Göttingen, Göttingen, Germany.

Collard, B. L., P. J. Boettcher, J. C. M. Dekkers, D. Petitclerc, and L. R. Schaeffer. 2000. Relationships between energy balance and health traits of dairy cattle in early lactation. J. Dairy Sci. 83:2683-2690. 
de Haas, Y., H. W. Barkema, and R. F. Veerkamp. 2002. Genetic parameters of pathogen-specific incidence of clinical mastitis in dairy cows. Anim. Sci. 74:233-242.

de Haas, Y., W. Ouweltjes, J. ten Napel, J. J. Windig, and G. de Jong. 2008. Alternative somatic cell count traits as mastitis indicators for genetic selection. J. Dairy Sci. 91:2501-2511.

Dempster, E. R., and I. M. Lerner. 1950. Heritability of threshold characters. Genetics 35:212-236.

Feucker, W., and R. Staufenbiel. 2003. Zentraler Diagnoseschlüsse Rind. Accessed Mar. 16, 2010. http://www.portal-rind.de/index. php? module $=$ Downloads\&func $=$ prep hand out\&lid $=17$.

Fleischer, P., M. Metzner, M. Beyerbach, M. Hoedemaker, and W. Klee. 2001. The relationship between milk yield and the incidence of some diseases in dairy cows. J. Dairy Sci. 84:2025-2035.

Frigo, E., C. D. Dechow, O. Pedron, and B. G. Cassell. 2010. The genetic relationship of body weight and early-lactation health disorders in two experimental herds. J. Dairy Sci. 93:1184-1192.

Gernand, E., R. Waßmuth, U. U. von Borstel, and S. König. 2007. Heterogeneity of variance components for production traits in large-scale dairy farms. Livest. Sci. 112:78-89.

Gianola, D., and D. Sorensen. 2004. Quantitative genetic models for describing simultaneous and recursive relationships between phenotypes. Genetics 167:1407-1424.

Harder, B., J. Bennewitz, D. Hinrichs, and E. Kalm. 2006. Genetic parameters for health traits and their relationship to different persistency traits in German Holstein dairy cattle. J. Dairy Sci. 89:3202-3212.

Heringstad, B., Y. M. Chang, D. Gianola, and G. Klemetsdal. 2004 Multivariate threshold model analysis of clinical mastitis in multiparous Norwegian dairy cattle. J. Dairy Sci. 87:3038-3046.

Heringstad, B., Y. M. Chang, D. Gianola, and G. Klemetsdal. 2005. Genetic analyses of clinical mastitis, milk fever, ketosis, and retained placenta in three lactations of Norwegian Red cows. J. Dairy Sci. 88:3273-3281.

Heringstad, B., G. Klemetsdal, and J. Ruane. 2000. Selection for mastitis resistance in dairy cattle-A review with focus on the situation in Nordic countries. Livest. Prod. Sci. 64:95-106.

Heringstad, B., G. Klemetsdal, and T. Steine. 2007. Selection responses for disease resistance in two selection experiments with Norwegian Red cows. J. Dairy Sci. 90:2419-2426.

Hinrichs, D., E. Stamer, W. Junge, and E. Kalm. 2005. Genetic analyses of mastitis data using animal threshold models and genetic correlations with production traits. J. Dairy Sci. 88:2260-2268.

Hooijer, G. A., R. B. F. Lubbers, B. J. Ducro, J. A. M. van Arendonk, L. M. T. E. Kaal-Lansbergen, and T. van der Lende. 2001. Genetic parameters for cystic ovarian disease in Dutch Black and White cattle. J. Dairy Sci. 84:286-291.

Hufe, P. 2003. Ansätze zur Senkung von Remontierungsraten in einem Milchviehbetrieb. Züchtungskunde 75:472-478.

Kehrli, M. E. Jr., and D. E. Shuster. 1994. Factors affecting milk somatic cells and their role in health of the bovine mammary gland. J. Dairy Sci. 77:619-627.

Koeck, A., B. Heringstad, C. Egger-Danner, C. Fuerst, P. Winter, and B. Fuerst-Waltl. 2010a. Genetic analysis of clinical mastitis and somatic cell count traits in Austrian Fleckvieh cows. J. Dairy Sci. 93:5987-5995

Koeck, A., B. Heringstad, C. Egger-Danner, C. Fuerst, and B. FuerstWaltl. 2010b. Comparison of different models for genetic analysis of clinical mastitis in Austrian Fleckvieh dual-purpose cows. J. Dairy Sci. 93:4351-4358.

Koenig, S., A. R. Sharifi, H. Wentrot, D. Landmann, M. Eise, and H. Simianer. 2005. Genetic parameters of claw and foot disorders estimated with logistic models. J. Dairy Sci. 88:3316-3325.
König, S., G. Dietl, I. Raeder, and H. H. Swalve. 2005b. Genetic relationships for dairy performance between large-scale and smallscale farm conditions. J. Dairy Sci. 88:4087-4096.

König, S., G. Hübner, R. Sharifi, E. Bohlsen, J. Detterer, H. Simianer, and W. Holtz. 2006. Relationship between somatic cell score and success of first inseminations in dairy cattle estimated with logistic models. Züchtungskunde 78:89-101.

König, S., and H. H. Swalve. 2006. A model calculation on the prospects of an improvement of claw health in dairy cattle via genetic selection. Züchtungskunde 78:345-356.

König, S., X. L. Wu, D. Gianola, B. Heringstad, and H. Simianer. 2008. Exploration of relationships between claw disorders and milk yield in Holstein cows via recursive linear and threshold Models. J. Dairy Sci. 91:395-406.

Mark, T. 2004. Applied genetic evaluations for production and functional traits in dairy cattle. J. Dairy Sci. 87:2641-2652.

Santos, J. E. P., R. L. Rainard, M. A. Ballou, G. E. Higginbotham, and J. E. Kirk. 2004. Effects of timing of first clinical mastitis occurrence on lactational and reproductive performance of Holstein dairy cows. Anim. Reprod. Sci. 80:31-45.

Schafberg, R., F. Rosner, and H. H. Swalve. 2006. Examinations on intramammary infections in dairy cows based on pathogen-specific data. Article 15-13 in Proc. 8th World Congr. Genet. Appl. Livest. Prod., Belo Horizonte, MG, Brazil. WCGALP Organizing Committee, Belo Horizonte, MG, Brazil.

Schalm, O. W., and D. O. Noorlander. 1957. Experiments and observations leading to development of the California mastitis test. J. Am. Vet. Med. Assoc. 130:199-204.

Schierenbeck, S., F. Reinhardt, R. Reents, H. Simianer, and S. König. 2011. Identification of informative cooperator herds for progeny testing based on yield deviations. J. Dairy Sci. 94:2071-2082.

Schrick, F. N., M. E. Hockett, A. M. Saxon, M. J. Lewis, H. H. Dowlen, and S. P. Oliver. 2001. Influence of subclinical mastitis during early lactation on reproductive parameters. J. Dairy Sci. $84: 1407-1412$

Simianer, H., and S. König. 2002. Ist Zucht auf Krankheitsresistenz erfolgreich? Züchtungskunde 74:413-425.

Tsuruta, S., I. Misztal, C. Huang, and T. J. Lawlor. 2009. Bivariate analysis of conception rates and test-day milk yields in Holsteins using a threshold-linear model with random regressions. J. Dairy Sci. 92:2922-2930.

Uribe, H. A., B. W. Kennedy, S. W. Martin, and D. F. Kelton. 1995 Genetic parameters for common health disorders of Holstein cows. J. Dairy Sci. 78:421-430.

Van Tassell, C.P., and L.D. Van Vleck. 1995. A set for FORTRAN programs to apply Gibbs sampling to animal models for variance component estimation. A Manual for Use of MTGSAM. US Department of Agriculture, Agricultural Research Service, Lincoln, NE.

Windig, J. J., W. Ouweltjes, J. ten Napel, G. de Jong, R. F. Veerkamp and Y. de Haas. 2010. Combining somatic cell count traits for optimal selection against mastitis. J. Dairy Sci. 93:1690-1701.

Wolf, V., H. Hamann, H. Scholz, and O. Distl. 2001. Einflüsse auf das Auftreten von Labmagenverlagerungen bei Deutschen Holstein Kühen. Dtsch. Tierarztl. Wochenschr. 108:403-408.

Zwald, N. R., K. A. Weigel, Y. M. Chang, R. D. Welper, and J. S. Clay. 2004. Genetic selection for health traits using producer recorded data. I. Incidence rates, heritability estimates, and sire breeding values. J. Dairy Sci. 87:4287-4294.

Zwald, N. R., K. A. Weigel, Y. M. Chang, R. D. Welper, and J. S. Clay. 2006. Genetic analysis of clinical mastitis data from onfarm management software using threshold models. J. Dairy Sci. $89: 330-336$. 